\title{
NOTES ON THE COMPLEMENT FIXATION REACTION IN GONORRHEA
}

By W. J. TULLOCH, O.B.E., M.D., Bacteriological Laboratory, University College, Dundee, University of St. Andrews.

THE complement fixation reaction is never likely to occupy the same important place in the diagnosis and control of treatment in gonorrhœa as does the Wassermann reaction in syphilis.

Nevertheless, that some such test is desired is evidenced by the multiplicity of methods advised for carrying out the complement fixation reaction in gonorrhœa. For this reason one hesitates to add yet another method to the already long list, but some points of importance have not, I think, been sufficiently stressed, and this is my excuse for calling attention to a technique which has been evolved in this laboratory for conducting the test under consideration.

The first of these points is that, owing to the poverty of humoral response in gonorrhœa, any technique employed must be of great delicacy if valuable information is to be obtained. That means that minimal quantities of complement must be used, and if that is so it is essential that the antigen employed in the test be devoid of anticomplementary qualities, so that false positive results may not occur owing to a summation of the anticomplementary qualities of the antigen and of the sera under investigation.

The second point is, that we have been too prone to regard each strain of the gonococcus as possessing remarkably specific antigenic characters, so that in preparing antigen for the test it has been customary to employ several strains. Agglutination and absorption of agglutinins, however, indicate that the majority (70 per cent.) of strains of the gonococcus conform to one serological type, while the work of Thomson and Vollmond (Acta Medica Scandinavica, I922, vol. 57, No. I) show that complement fixation is not markedly specific in relation to 


\section{BRITISH JOURNAL OF VENEREAL DISEASES}

the serological types of the gonococcus, so that it is unnecessary and adds complexity to the test to include more than one strain in the antigen.

In preparing an antigen for the test we should, therefore, use a strain : (i.) which has been proved by the absorption of agglutinins reaction to belong to the predominant type ; and (ii.) which on culture does not develop anticomplementary qualities. It is to be noted that the less frequently found types tend to be more anticomplementary than the predominant type, and it has been my experience that the longer the micro-organism is cultivated before the antigen is made the more anticomplementary does it become. By this is meant that the individual cultures, not the strain, as maintained in stock culture, become anticomplementary.

The medium used for preparing the growths is that devised by Torrey and Buckell (Jour. of Inf. Diseases, vol. 3I, No. 2, pp. I25-I47), but to ensure rapid growth 0.5 c.c. of Io per cent. sterile citrated rabbit plasma is added to each tube (8 c.c.) of agar melted and cooled to $50^{\circ} \mathrm{C}$., then sloped.

To obtain rapid growths one proceeds thus : a tube of the Torrey Buckell medium, enriched with plasma, is heated to $37^{\circ} \mathrm{C}$., is inoculated from the stock culture chosen, and is incubated overnight at $37^{\circ} \mathrm{C}$. The following morning six slope tubes $\left(6 \times \frac{3}{4}\right)$ of the same medium are heated to $37^{\circ} \mathrm{C}$., and are inoculated from the culture prepared the previous night. These tubes after about six hours incubation will show a fine confluent growth. This very young growth is washed off with saline, I c.c. being used for each tube. The resulting suspension is left frozen and serves as the stock antigen, being melted only to allow of removal of quantities to be diluted for the actual tests.

The stock suspension thus prepared when diluted in saline $I$ in 20 gives a suspension which, estimated by the opacity method, usually contains between 500 and I,000 million cocci per cubic centimetre. Thus diluted, it is ready for use provided that the strain used for its preparation is satisfactory. Further dilution should be avoided and, if the suspension diluted I in 20 exhibits anticomplementary qualities, another strain used.

Before any batch of antigen is accepted for use in the reaction it is tested from this standpoint, the method 


\section{BRITISH JOURNAL OF VENEREAL DISEASES}

used being as follows : two rows of eight tubes are set up as in the following chart, and reagents are measured into them as indicated. They are then incubated at $37^{\circ} \mathrm{C}$. in the air incubator, for two hours, when 0.25 c.c. of 2.5 per cent. suspension of sensitised sheep cells are added to each.

Incubation at $37^{\circ} \mathrm{C}$. is continued in the water bath for thirty minutes, when readings are taken, the m.h.d. of the complement being the smallest quantity of that reagent which produces complete lysis under the condition of this preliminary test.

Note I. - The complement should be a mixed complement derived from at least three guinea pigs, and before use it must be absorbed with sheep cells thus : to each I c.c. of complement is added O.I c.c. of the deposit of washed sheep cells obtained by centrifugalisation. The cream of red cells added to the complement is well mixed therewith, and left in contact for two hours, after which the mixture is again centrifuged and the clear " absorbed " complement is pipetted off.

Note 2.- In sensitising the red cells 2.5 times the m.h.d. of anticorpuscle serum is employed, the m.h.d. of this reagent being determined by the method employed for its standardisation in the Fildes McIntosh method of conducting the Wassermann reaction.

(I) Preliminary Test.

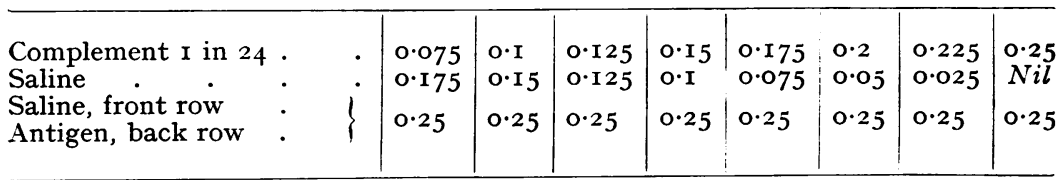

Incubate two hours at $37^{\circ} \mathrm{C}$., then add sensitised cells. Then incubate in water bath thirty minutes at $37^{\circ} \mathrm{C}$.

If the complement is satisfactory lysis will be complete in one of the first four tubes, reading from left to right. If complete in the fifth tube it may be used, but unsatisfactory reactions are liable to occur if the m.h.d. is higher than that indicated by complete lysis in this (fifth) tube.

If the antigen is satisfactory lysis in the tubes of the back row should be the same as, although sometimes a little slower than, those in the front row, i.e. if lysis be complete in the third tube from the left without antigen, 


\section{BRITISH JOURNAL OF VENEREAL DISEASES}

it should also be complete in the third tube from the left in presence of antigen.

Occasionally lysis will be complete only in the fourth tube in the back row when it is complete in the third in the front row, and when this happens the antigen can be used, the m.h.d. being taken as corresponding to the fourth tube, but no further deviation of the reaction to the right in the back row can be allowed, and if it does occur the complement is unsuitable.

The sera to be tested should be inactivated at $55^{\circ} \mathrm{C}$. for twenty minutes on receipt at the laboratory, stored at $0^{\circ} \mathrm{C}$. till the day when the tests are to be made, and again inactivated for twenty minutes on the morning of the test. It is absolutely essential that positive and negative controls be included in each batch of tests; these can be retained from previous batches, as in doing the Wassermann reaction;--while it is advisable also to have a positive control rabbit serum derived from a rabbit which has been immunised against a "predominant type" gonococcus. This serum is used diluted $\mathrm{I}$ in 20 .

In setting up the tests four tubes are used for the examination of each serum. These tubes contain :-

Tube $(a) .0 .025$ c.c. serum to be tested.

0.25 c.c. saline.

I.5 m.h.d. complement, volume $=0 \cdot 25$ c.c.

Tube $(b) .0 .05$ c.c. serum to be tested. Front row. 0.25 c.c. saline.

2 m.h.d. complement, volume $=0 \cdot 25$ c.c.

Tube $(c) .0 \cdot 025$ c.c. serum to be tested.

0.25 c.c. antigen.

I.5 m.h.d. complement, volume $=0.25$ c.c.

Tube (d). 0.05 c.c. serum to be tested. Back row. 0.25 c.c. antigen.

2 m.h.d. complement, volume $=0 \cdot 25$ c.c.

The mixtures are incubated for two hours at $37^{\circ} \mathrm{C}$., and 0.25 c.c. of " $2 \frac{1}{2}$ times sensitised " 2.5 per cent. suspension of sheep cells added to each tube. Incubation in a water bath is continued for forty-five minutes, when the results may usually be read, but occasionally incubation for sixty minutes is required.

(The following chart gives the quantities of complement required for conducting twenty-four tests.) 


\section{BRITISH JOURNAL OF VENEREAL DISEASES}

(2) On above titration the following are needed for twenty-four tests, allowing 2 m.h.d. and I.5 m.h.d.

\begin{tabular}{|c|c|c|c|c|c|c|c|c|c|}
\hline $\begin{array}{c}2 \text { m.h.d. : } \\
\text { Undiluted } \\
\text { plement } \\
\text { Saline. }\end{array}$ & $\begin{array}{r}\text { Com- } \\
\cdot \\
\cdot\end{array}$ & $\begin{array}{r}0 \cdot 3 \\
\text { I I } \cdot 7\end{array}$ & $\begin{array}{r}0.4 \\
\mathrm{II} \cdot 6\end{array}$ & $\begin{array}{r}0 \cdot 5 \\
\mathrm{I} 1 \cdot 5\end{array}$ & $\begin{array}{r}0 \cdot 6 \\
11 \cdot 4\end{array}$ & $\begin{array}{r}0 \cdot 7 \\
\text { I } 1 \cdot 3\end{array}$ & $\begin{array}{r}0.8 \\
\mathrm{r} \cdot 2 \cdot 2\end{array}$ & $\begin{array}{r}0 \cdot 9 \\
I I \cdot 1\end{array}$ & $\begin{array}{r}\mathbf{I} \\
\mathbf{I} \mathbf{I}\end{array}$ \\
\hline $\begin{array}{l}\text { I’5 m.h.d. : } \\
\text { Undiluted } \\
\text { plement } \\
\text { Saline. }\end{array}$ & $\begin{array}{r}\text { Com- } \\
\text { - }\end{array}$ & $\begin{array}{r}0.225 \\
\mathrm{I} \mathbf{1} \cdot 775\end{array}$ & $\begin{array}{r}0.3 \\
11 \cdot 7\end{array}$ & $\begin{array}{r}0.375 \\
\mathrm{I} 1.625\end{array}$ & $\begin{array}{r}0.45 \\
\text { II. } 55\end{array}$ & $\begin{array}{r}0.525 \\
\mathrm{II} \cdot 475\end{array}$ & $\begin{array}{r}0.6 \\
\mathrm{II} \cdot 4\end{array}$ & $\begin{array}{r}0.675 \\
\text { II.322 }\end{array}$ & $\begin{array}{r}0.75 \\
\text { II } 25\end{array}$ \\
\hline
\end{tabular}

In interpreting the results obtained the following points are to be noted :-

(i.) If there is complete inhibition of lysis in both back row tubes and complete lysis in both front row tubes the reaction is regarded as strongly positive and, provided that the controls are satisfactory, is of definite diagnostic significance.

(ii.) If all four tubes show complete lysis, the reaction is negative, but this, of course, is of minor diagnostic significance, as in early acute gonorrhœa and in what one might term circumscribed latent gonococcal infection a negative result is to be expected.

(iii.) If both back row tubes show over 50 per cent. inhibition of lysis, and both front row tubes are completely lysed, the result is to be regarded as "suspicious but not of definite diagnostic significance.'

(iv.) If tube (c) of back row shows complete fixation and (d) only partial fixation, while $(a)$ and $(b)$ both show comPLETE lysis, the reaction is to be regarded as positive but feeble.

(v.) If tubes $(c)$ and $(d)$ both show complete fixation, while $(a)$ shows some inhibition of lysis and $(b)$ complete lysis, a provisional positive report may be given, but a request for a further examination should accompany this, as such reactions cannot be regarded as entirely satisfactory.

(vi.) If tube (b) shows some inhibition of lysis the serum should be reported as antihæmolytic unless the same degree of lysis is present in tube $(d)$, when a provisional negative report may be given.

Using the technique described and interpreting the results according to the above notes, the following results have been obtained.

The total number of cases in our series in which clinical observation was available as a control of serological 


\section{BRITISH JOURNAL OF VENEREAL DISEASES}

investigation is to date 696 , and the results obtained may be discussed as follows :-

(A) Does the occurrence of a positive Wassermann reaction in the serum to be examined invalidate the gonococcus fixation reaction? This question may at first glance appear to be unnecessary, but it must be borne in mind that the Wassermann test is dependent upon (presumably) an interaction of an "heterogenetic" nature, and it would therefore be well to show that the lipoids of the gonococcus do not act as a Wassermann "antigen."

In the series under consideration both Wassermann test and fixation reaction were performed with the same serum in 50I instances, and the results were distributed thus :-

$$
\begin{aligned}
& \text { (a) Wassermann - fixation - } 240 \\
& \text { (b) Wassermann + fixation + } 65 \\
& \text { (c) Wassermann + fixation - } 55 \\
& \text { (d) Wassermann - fixation + } \frac{\text { I } 4 \mathrm{I}}{5 \mathrm{OI}}
\end{aligned}
$$

There is a "positive agreement" then between the results of both tests in 65 instances $(b)$, out of 260 tests (b) $(c)$ and $(d)$, but of these 65 there were 44 in which microscopical examination of the discharges was positive for gonococci, leaving 2I in which the possibility of a false positive reaction arises, but of these $2 \mathrm{I}$, I4 were cases of long standing gleet where there was an indubitable history of gonorrhoea, so leaving only 7 out of $26 \mathrm{I}$ in which it might be argued that a false positive fixation reaction had resulted from the presence of a Wassermann reacting serum in the test.

(B) What evidence is there that a positive reaction obtained by the method described is of diagnostic significance?

In the series under consideration both fixation reaction and microscopical examinations had been made upon the same patient in 56I instances, and the results obtained were these :-

(a) Fixation reaction + microscopical findings +206

(b) Fixation reaction - microscopical findings - 244

(c) Fixation reaction + microscopical findings - 48

(d) Fixation reaction - microscopical findings +63 


\section{BRITISH JOURNAL OF VENEREAL DISEASES}

There are then II 8 discrepancies $(c)$ and $(d)$ between the findings of the two methods, and on inquiring into these the following facts are brought to light.

(i.) In the first place considering $(d)$, which might be regarded as evidence that the test lacked delicacy, it is found that-

(I) In 45 instances the blood was from acute cases of less than two weeks duration.

(2) In ro instances the history was over two weeks but less than two months.

(3) In I instance an interval of three months had elapsed since a positive microscopical examination had been obtained.

(4) In I instance an interval of six months had elapsed since a positive microscopical examination had been obtained.

(5) In I instance an interval of seven months had elapsed since a positive microscopical examination had been obtained.

(6) In 2 instances an interval of one year had elapsed since a positive microscopical examination had been obtained.

(7) In 2 instances an interval of two years had elapsed since a positive microscopical examination had been obtained.

(8) In I instance the history of onset was indefiniteThe last eight $\left(3^{-8)}\right.$ were all females.

63

We may, I think, exclude the cases under heading (I), supra, because of the short history, and also those under (6) and (7) because of the length of the period intervening between microscopical examination of discharges and the performance of the fixation test, leaving fourteen cases out of $56 \mathrm{I}$ in which it may be argued that the test showed a serious lack of delicacy.

(ii.) Secondly considering $(c)$, we are met with a more important argument, viz. that these forty-eight cases represent errors on the positive side, i.e. false positive reactions.

It is significant that of these, two-thirds, thirty-two, were specimens from female cases and all had been sent 


\section{BRITISH JOURNAL OF VENEREAL DISEASES}

for investigation either because a definite history of gonorrhœa was obtained or was strongly suspected. Moreover, a negative microscopical examination in the female is not of the same significance as in the male, and in three instances among these cases the fact that the patient was infected was proved by infectivity.

Of the sixteen males in this category twelve suffered from gleet, in two instances epididymitis was present, and one was a case of gonococcal arthritis.

(C) How frequently is the test rendered invalid because the serum for examination possesses anticomplementary qualities?

As only a small multiple (I.5 and 2) of the m.h.d. is used in carrying out the tests it is to be expected that a fair percentage of specimens of serum will exhibit anticomplementary qualities, and if this be too great the value of the test would be much reduced.

In the series of cases under consideration the serum from forty-three exhibited anticomplementary qualities, i.e. 43 out of 696 , i.e. about 6 per cent.-a figure which is not high considering the technique of the reaction.

(D) There $r \in$ main ninety-two serums in which fixation tests were carried out without microscopical examination having been made.

The distribution of these is as follows :-

(a) In fifty-eight, all of which were sent for controlling the test, the fixation reaction was negative.

(b) There remain thirty-four in which a positive fixation reaction was obtained, no microscopical examination having been made.

So far as I have been able to establish, in only two of these was there really serious doubt as to the nature of the case, and therefore results obtained with these two specimens should frankly be regarded as errors due to technique.

Summarising these results it may be stated :-

I. That sera giving a positive reaction with the Wassermann test do not give false positive reactions when used for the gonococcus fixation test, the figures showing a maximum probable error of 7 in $26 \mathrm{I}=2 \cdot 6$ per cent.

II. That the test appears to give markedly specific results. The most serious discrepancies between fixation tests and microscopical findings are those instances in which fixation is positive and microscopical findings are 


\section{BRITISH JOURNAL OF VENEREAL DISEASES}

negative. These number forty-eight, but the clinical evidence of gonorrhœea in eighteen of these-three females and fifteen males-is unequivocal, while in the remaining thirty-all female-the presumption of gonococcal infection is strong. If then we accept these thirty as evidence of error inherent in the technique the maximum error due thereto is thirty in $56 \mathrm{I}$-an error of approximately 6 per cent.

III. That the test is one of considerable delicacy is shown by the fact that in the majority of these cases in which a negative fixation reaction was obtained along with positive microscopical findings the disease was in the early acute stage.

In conclusion I have to record my thanks to Dr. A. Laird and Dr. C. Averill, medical officers of the V. D. Clinic of the City of Dundee, and also to Dr. W. Alexander, who acted for some time as medical officer of that clinic, for supplying me with material for investigation and notes of the clinical condition of their cases.

The findings herein recorded constitute part of an investigation on gonorrhœa which is being carried out on behalf of the Medical Research Council, and to this body also I desire to record my thanks. 